\title{
Memory for auditorily and visually presented commericals: Effects of repetition and type of claim
}

\author{
LINDA A. MADY and SLATER E. NEWMAN \\ North Carolina State University, Raleigh, North Carolina
}

\begin{abstract}
In Experiment 1 subjects were tested on asserted and implied claims after each of two auditory presentations of a set of commercials. The same procedure was used in Experiment 2, except that the commercials were presented visually. In both experiments, subjects were able to differentiate between the asserted and the implied claims on each test, and there was a greater tendency (significant in Experiment 2 and approaching significance in Experiment 1) to accept the claims on the second than on the first test.
\end{abstract}

Previous research (Harris, 1977; Searleman \& Carter, 1984) has shown that when subjects listen to commercials that assert a claim and others that imply a claim, they are likely to remember the implications as if they were assertions. When commercials are repeated a second time, subjects are even more likely to accept as true both those statements that assert a claim (as would be expected), and those that imply a claim (Bruno \& Harris, 1980). Subsequent repetition of either type of commercial has been found to add only slightly to subjects' acceptance of their claims as true (Bruno \& Harris, 1980).

The effects of repetition and type of claim were examined in the two experiments reported here. In Experiment 1 , the commercials were presented auditorily, as in previous studies (Bruno \& Harris, 1980; Harris, 1977; Searleman \& Carter, 1984), whereas in Experiment 2 the commercials were presented visually. In both experiments, we were interested in the extent to which asserted claims would be differentiated from implied claims after both the first and the second presentation and, concomitantly, whether similar results would be obtained for the two modalities.

\section{EXPERIMENT 1}

\section{Method}

Materials. The commercials and test questions were those used by Searleman and Carter (1984). Commercials between 30 and 66 words in length (mean $=44$ ) were prepared for 16 fictitious products. One version of each commercial asserted a claim (Type A) and one implied

These experiments were performed by the first author as an undergraduate research project under the supervision of the second author. We very much appreciate the help of Alan Searleman, who provided us with the instructions, commercials, and test questions used in his experiment. A paper describing our results was presented in March 1985 at the annual meeting of the Eastern Psychological Association in Boston. Requests for reprints should be sent to Slater E. Newman, Department of Psychology, Box 7801, North Carolina State University, Raleigh, NC 27695-7801. a similar claim (Type I). The commercials were presented on tape. Two sets of tapes were prepared. Each set contained 16 commercials, 8 of Type A and 8 of Type I. Those commercials that appeared as Type A in one set appeared as Type $I$ in the other, and vice versa. Two orders of the commercials were prepared for each set.

On the test there were 32 statements, 2 for each commercial. They were presented in a test packet, one statement to a page. The subjects were required to answer, on the basis of the commercials that had just been presented, "true," "false," or "indeterminate" to each statement. One of the two statements pertaining to each commercial was a filler to which the correct answer was "false" or "indeterminate." The other statement had been asserted in the Type A commercial but only implied in the Type I commercial; thus, it would be correctly marked "true" only by those exposed to the Type A commercial. These 16 statements appeared on the test in the order in which their commercials had appeared on the study trials.

Procedure. The subjects heard all of the 16 commercials (study trials) and were then tested. A second presentation and test followed immediately. As in previous experiments (Bruno \& Harris, 1980; Harris, 1977; Searleman \& Carter, 1984), the subjects were instructed to accept as true what was stated in each commercial.

Subjects. There were 19 subjects. All were students enrolled in the introductory course in psychology on our campus.

\section{Results}

The mean number of statements marked "true" for Type A and Type I items on each test is presented in Table 1 . All means are significantly greater than chance $(p<.01)$. An analysis of variance showed that only the effect for type of claim was significant $[F(1,18)=35.45$, $p<.001, M S e=1.52]$, although the effect of repetition approached significance $[F(1,18)=3.06$, $.10>p>.05, M S e=1.72]$. Examination of the means shows that on each test there were more "true" responses for Type A than for Type I items, and that there was a

Table 1

Mean Number of Statements Marked "True" as a Function of Repetition and Type of Claim: Experiment 1

\begin{tabular}{lcc}
\hline & Test 1 & Test 2 \\
\hline Assertion & 6.58 & 7.37 \\
Implication & 5.16 & 5.42 \\
\hline
\end{tabular}


Table 2

Mean Number of Statements Marked "True" as a Function of Repetition and Type of Claim: Experiment 2

\begin{tabular}{lcc}
\hline & Test 1 & Test 2 \\
\hline Assertion & 6.32 & 7.21 \\
Implication & 5.32 & 5.53 \\
\hline
\end{tabular}

tendency (although not significant) for the number of "true" responses to increase from the first to the second test.

\section{EXPERIMENT 2}

\section{Method}

The method was the same as that of Experiment 1, except that the commercials were presented visually. Each was available for $15 \mathrm{sec}$. The 19 subjects were from the same population as those who served in Experiment 1.

\section{Results}

Table 2 presents the mean number of statements marked "true" for Type A and Type I items on the first and second tests. Again, all means were found to be significantly greater than chance $(p<.01)$. The analysis of variance showed that both of the main effects (but not their interaction) were significant [for type of claim, $F(1,18)$ $=15.55, p<.001, M S e=2.20$; for repetition, $F(1,18)$ $=8.06, p<.05, M S e=.72]$. Again there were more "true" responses for Type A than for Type I items on each test. This time, however, the number of "true" responses was significantly greater on the second than on the first test.

\section{GENERAL DISCUSSION}

The following results were obtained in both experiments: (1) In each condition there were more "true" responses than would be expected by chance, (2) asserted claims were more often accepted as true than were implied claims on each test, and (3) repetition of a claim enhanced the probability that it would be recalled as true (although this effect was not significant for the auditory commercials).

The effect of repetition is similar to that reported by Bruno and Harris (1980), whose subjects heard each commercial repeated in a session 2 days after first hearing it, rather than (as in our experiments) hearing it repeated in the same session. In their study, both asserted and implied claims were more likely to be accepted as true after the second than after the first presentation. As in both of our experiments, the increase was somewhat (although not significantly) greater for asserted than for implied claims.

There is one other difference between our results and those of previous studies (Harris, 1977; Searleman \& Carter, 1984): our subjects were more likely than those in previous studies to discriminate between asserted and implied claims. In Searleman and Carter's (1984) experiment, however, the difference approached significance. Furthermore, when their subjects were tested immediately after hearing a commercial, the number of "true" responses for asserted claims was greater than that for implied claims. A similar tendency was reported by Harris (1977), although it was not significant.

Our results suggest that similar processes may be operative in recall from commercials presented auditorily and those presented visually. Furthermore, our results, combined with those of Bruno and Harris (1980), suggest that repetition of a claim, in either modality, enhances the probability that it will be remembered as true; the effect occurs for claims that are asserted and, although probably to a lesser extent, for claims that are implied.

\section{REFERENCES}

Bruno, K. J., \& Harris, R. J. (1980). The effect of repetition on the discrimination of asserted and implied claims in advertising. Applied Psycholinguistics, 1, 307-321.

HARRIS, R. J. (1977). Comprehension of pragmatic implications in advertising. Journal of Applied Psychology, 62, 603-608.

Searleman, A., \& CarTer, H. (1984, April). The effectiveness of different types of pragmatic implications in commercials. Paper presented at the meeting of the Eastern Psychological Association, Baltimore, MD.

(Manuscript received for publication September 13, 1986.) 